\title{
Hydrodynamic modelling and characterisation of a shallow fluvial lake: a study on the Superior Lake of Mantua
}

\author{
Andrea FENOCCHI, ${ }^{*}$ Stefano SIBILLA \\ Department of Civil Engineering and Architecture, University of Pavia, Via Ferrata 3, 27100 Pavia, Italy \\ *Corresponding author: andrea.fenocchi@unipv.it
}

\begin{abstract}
This paper presents a numerical modelling framework developed to simulate circulations and to generally characterise the hydrodynamics of the Superior Lake of Mantua, a shallow fluvial lake in Northern Italy. Such eutrophied basin is characterised by low winds, reduced discharges during the summer and by the presence of large lotus flower (Nelumbo nucifera) meadows, all contributing to water stagnation. A numerical hydrodynamic model was built to understand how physical drivers shape basic circulation dynamics, selecting appropriate methodologies for the lake. These include a $3 D$ code to reproduce the interaction between wind and through-flowing current, a fetch-dependent wind stress model, a porous media approach for canopy flow resistance and the consideration of wave-current interaction. The model allowed to estimate the circulation modes and water residence time distributions under identified typical ordinary, storm and drought conditions, the hydrodynamic influence of the newly-opened secondary outlet of the lake, the surface wave parameters, their influence on circulations and the bottom stress they originate, and the adaptation time scales of circulations to storm events. Some probable effects of the obtained hydrodynamic characteristics of the Superior Lake of Mantua on its biochemical processes are also introduced.
\end{abstract}

Key words: Shallow fluvial lakes; lake hydrodynamics; numerical modeling; wind stress; vegetation resistance; lake circulations.

Received: October 2015. Accepted: March 2016.

\section{INTRODUCTION}

Shallow lakes are very dynamic water bodies, exhibiting strong variations both in time and space of the algal biomass concentration. This is due to: i) the sensitivity to storm events, as the wind stress is able to advect and mix the whole flow depth, causing resuspension on the bottom (Luettich et al., 1990; Borell Lövstedt and Bengtsson, 2008), which in turn produces the opposed phenomena of increased nutrient availability and light limitation (Luettich et al., 1990; Bresciani et al., 2013); ii) the brief adaptation time scales of circulations to variations in the wind conditions, which are in the order of a few hours (Ciraolo et al., 2004), rapidly changing the advection dynamics.

Fluvial lakes, i.e. shallow basins with perceptible through-flowing current (Neuendorf et al., 2005), have an even more dynamic behaviour, circulations being shaped by the interaction between wind and discharge, with variable influences according to their relative intensity and direction (Anderson et al., 2010; Schimmelpfennig et al., 2012). Being often located in the lowland reach of river basins, where nutrient loads are maximum, they are extremely sensitive to discharge reductions, caused by meteorology and water diversion. This increase of water residence times causes phytoplankton blooms because of water stagnation and nutrient accumulation (Pinardi et al.,
2015). In addition, the much shorter time scale of advection, still in the order of a few hours (George and Heaney, 1978; Jones et al., 1995; de Souza Cardoso and da Motta Marques, 2009), compared to the one of algal growth and decay, reasonably $\sim 10 \mathrm{~d}$ (Verhagen, 1994), causes circulations to be the major drivers of phytoplankton and zooplankton distribution (Wiens, 1989; Pinel-Alloul, 1995). This results in horizontal concentration patchiness in lakes with prevailing planimetric circulations, which are typical of fluvial lakes. The evaluation of the hydrodynamic behaviour of a shallow fluvial lake would then support the understanding of its dynamic ecosystemical processes, providing their physical bases and allowing to go beyond black-box ecological models.

While the hydrodynamics of ordinary shallow lakes have been widely studied numerically (see e.g. Hodges, 2014 for a list of references), fluvial lakes have received less attention (Rubbert and Köngeter, 2005; Anderson et al., 2010; Schimmelpfennig et al., 2012), so that knowledge about their circulation modes and their modelling is weaker. This paper describes the setup and application of a numerical model aimed at reproducing the significant physical features shaping circulations in the Superior Lake of Mantua, a small shallow fluvial lake in Northern Italy which hosts vast lotus flower (Nelumbo nucifera) canopies.

The work: i) describes in the Methods section the el- 
ements of the modelling framework, which can be used as reference for other studies on similar basins; ii) analyses in the Results and Discussion section the outcomes of simulations performed to investigate specific hydrodynamic features of the basin, useful for future studies on this lake, in addition to pointing out some common characters of fluvial lakes. While a direct validation of the model by means of current measurements is presently lacking, a study on the inference of the hydrodynamics on phytoplankton distribution in the Superior Lake of Mantua, featuring an indirect validation by comparing the simulated flow fields to maps of chlorophyll- $a$ obtained from remote-sensing, was reported in Pinardi et al. (2015).

\section{METHODS}

\section{Study site}

The Superior Lake of Mantua is the most upstream of three cascading shallow fluvial lakes, formed by the control of the Mincio River around the city of Mantua (Fig. 1a) at the end of XII century AD. Renaturalisation of both the ecosystem and the geomorphology has since largely occurred. The basin, whose basic properties are listed in Tab. 1, is of elongated shape, widening in the downstream direction (Fig. 1). The inlet is not clearly defined, as gradual transition from the upstream Valli del Mincio wetlands occurs. The downstream boundary is provided by the Ponte dei Mulini dam, outflow occurring from two sluice gates (Fig. 2), ensuring the control water elevation of $17.50 \mathrm{~m}$ asl, $3 \mathrm{~m}$ above the lower basins: Vasarone, in the northern part of the dam, and the Vasarina on the opposite side, the latter activated in June 2015 for hydroelectric use. The large assemblies of lotus flower, introduced in 1921 , strongly influence the biogeochemical processes of primary production (Bolpagni et al., 2014). The bathymetry of the lake (Fig. 1b) has a bifurcated geometry, with two channels on the sides of a shallower central region, where the main lotus flower island took root. The latter has currently an extension of $35.5 \mathrm{ha}, \sim 10 \%$ of the lake total surface, since 2007 trimmed and subdivided by interposed canals (Fig. 2), which were aimed at favouring water circulation. The Mantua Lakes have been permanently eutrophied since the early 1980 s, because of intensive agriculture and livestock and the input of large treated wastewater discharges.

Being located in the southern Po River Plain, far from mountains and sea, the Mantua Lakes are subject to light winds, not controlled by daily thermal patterns, but rather the result of meso-scale air movements, usually taking place over a multi-daily time scale. The mean annual dis-

Tab. 1. Basic properties of the Superior Lake of Mantua.

\begin{tabular}{lc} 
Parameter & Value \\
Area $\left(\mathrm{km}^{2}\right)$ & 3.67 \\
Volume $\left(\mathrm{mm}^{3}\right)$ & 14.5 \\
\hline Average depth $(\mathrm{m})$ & 3.6 \\
Average annual discharge $\left(\mathrm{m}^{3} \mathrm{~s}^{-1}\right)$ & 20 \\
\hline Theoretical residence time $(\mathrm{d})$ & 8.4 \\
\hline
\end{tabular}

Data by OLL, 2005 and Bolpagni et al., 2014.
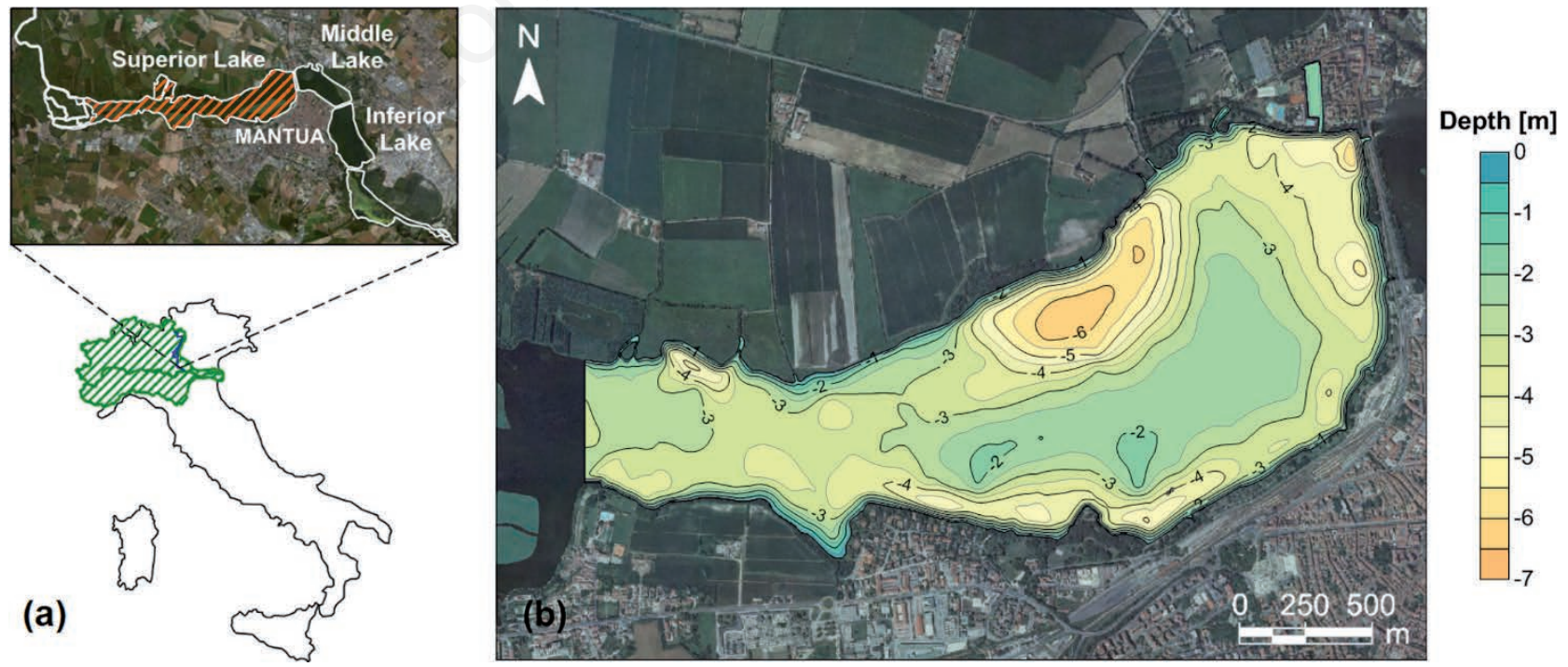

Fig. 1. a) Position of the Superior Lake of Mantua in the Po River basin and in the Mantua Lakes system. b) Bathymetry of the modelled portion of the lake. Adapted from Pinardi et al. (2015), Water 7:1921-1942; orthophotos provided by the Lombardy Region. 
charge passing through the lakes is $Q=20 \mathrm{~m}^{3} \mathrm{~s}^{-1}$ (Bolpagni et al., 2014), halving during the summer. Flows as low as $Q=2 \mathrm{~m}^{3} \mathrm{~s}^{-1}$ can be reached in extreme drought periods, such as during summer 2007 (Pinardi et al., 2011).

\section{Hydrodynamic model}

Despite flow shallowness, prevailing circulations in the horizontal plane and affinity to riverine environments, depth-averaged models are not properly suited to shallow fluvial lakes, as they incorrectly consider wind stress as a volume force (Teeter et al., 2001), evenly applied over the flow depth. Hence, they neglect surface stress transmission along the water depth through vertical turbulence, as well as differential velocity directions along the flow depth. This causes a severe underestimation of the influence of wind on circulations under strong interacting conditions between the wind and the riverine current, e.g., for the low winds common to basins in lowland areas (Fenocchi et al., 2016). Use of 3D models, as in Rubbert and Köngeter (2005) and Anderson et al. (2010), is therefore advised for these basins, also as simulation times are nowadays adequate (Fenocchi et al., 2016).

In this work, we employed STAR-CCM+ ver. 9.02 (CD-adapco, 2014), which integrates the incompressible Reynolds-Averaged Navier-Stokes (RANS) equations through a Finite Volume (FV), $2^{\text {nd }}-$ order accurate upwind method. The momentum and continuity equations are solved sequentially through a projection method, based on the SIMPLE algorithm. A Realisable $k-\varepsilon$ turbulence model (Shih et al., 1994) was used. For the complete adopted hydrodynamic equations, see Fenocchi (2015). Despite flows in shallow lakes are usually only weakly turbulent as regards circulations in the horizontal plane $\left(\operatorname{Re} \approx 10^{5}-10^{6}\right)$, shear layers produced by wind stress transmission and differences in the velocity direction along the water depth cause relevant turbulence effects in the vertical plane, justifying the use of a two-equation 3D turbulence model (Falconer et al., 1991).

\section{Geometry and meshing}

The 3D geometry of the Superior Lake of Mantua model is based on a 2006 sounding line bathymetrical survey (average resolution $\sim 167 \mathrm{~m}$ ), aided by a 2012 orthophoto for outlining the shorelines and the borders of the main lotus flower island (Fig. 2). The Kriging-interpolated bathymetry is shown in Fig. $1 \mathrm{~b}$.

Due to limited topographical data, only the actual lacustrine part of the lake is modelled (Fig. 2), leaving out the transitional channelised upstream reach. We thus introduced a fictitious inlet boundary, which we estimated to affect the results in the $\sim 500 \mathrm{~m}$ long upstream portion of the model. However, flow is still mostly river-like in that reach, except for drought discharges, so that the impairment of results is reduced.

The upper boundary of the model is provided by a fixed horizontal surface at the control elevation of the

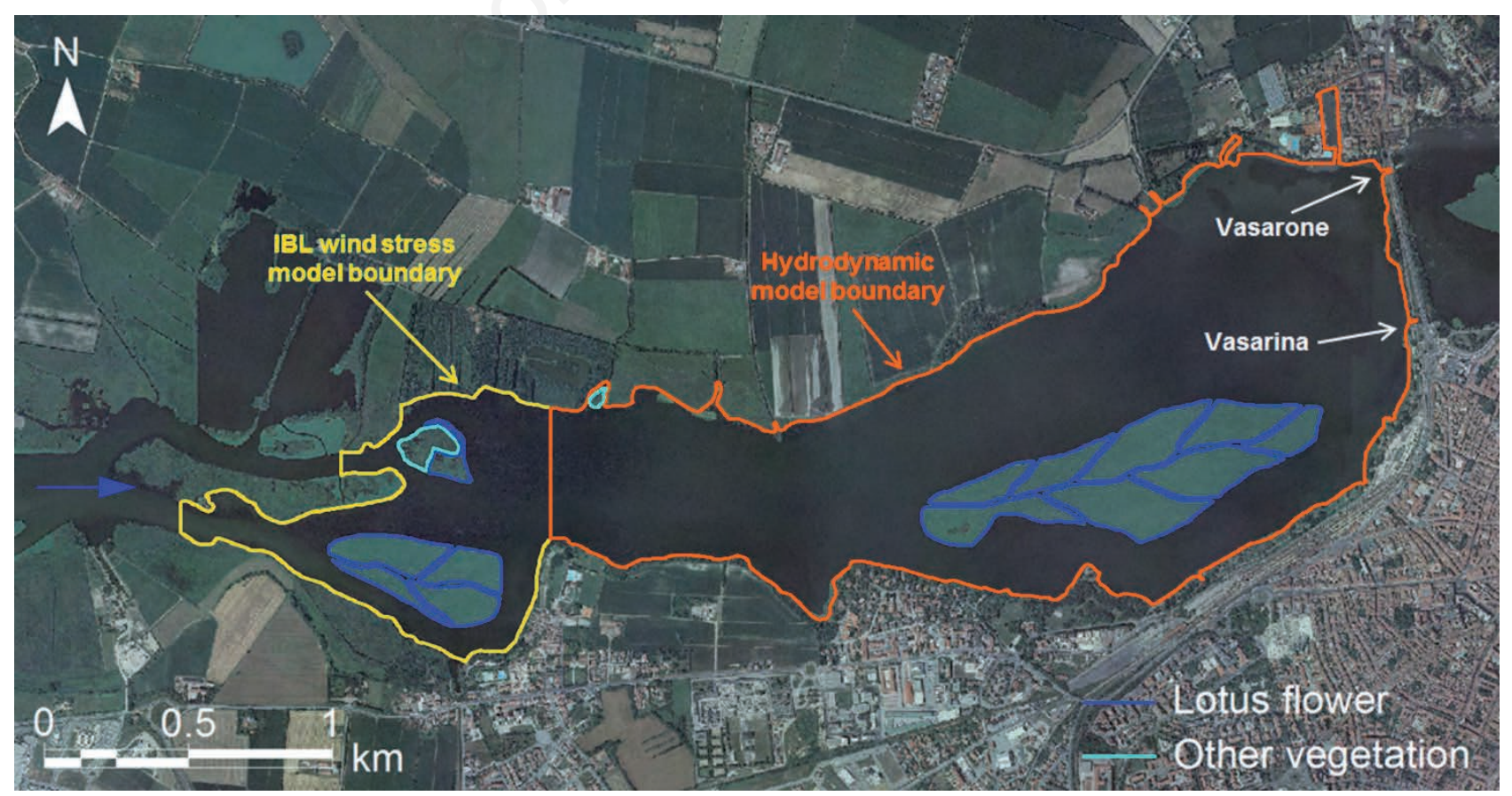

Fig. 2. Limits of the hydrodynamic and of the IBL wind stress models, and boundaries of the vegetated regions. 
lake: this is a reasonable assumption, since the free surface variations due to wind setup, head losses and pull effect near the outlets are much smaller than the grid vertical resolution (Wang et al., 2001). Therefore, more computationally expensive techniques which allow to track the moving boundary, such as Volumes of Fluids (VOF), are not needed here. Free surface variations were nevertheless estimated from the non-zero computed pressures at the surface boundary.

A grid with trimmed parallelepipedal cells with $\Delta x_{g}=6$ $\mathrm{m}$ horizontal resolution and $\Delta z_{g}=0.3 \mathrm{~m}$ vertical resolution, i.e. having aspect ratio $r_{g}=20$, was selected after preliminary simulations. Having fixed the vertical resolution, smaller aspect ratios did not result in improved accuracy (Fenocchi, 2015). If a wall-law approach is used for the bottom boundary layer, as suitable in most cases, the roughness height $k_{s}$ sets the lower limit of the vertical resolution for the bottom cells. In fact, physical results are obtained only provided that the roughness height is below the cell centroid. Excessive aspect ratios are also prone to cause numerical instabilities.

\section{Boundary conditions}

A slip wall condition was set at the fixed free surface boundary and wind stress was applied over the first surface layer of cells. On the bottom layer, friction was set according to a turbulent wall-law. A roughness height $k_{s}=0.075 \mathrm{~m}$ was adopted (Krámer, 2006). Sediments in the Superior Lake of Mantua are fine-grained, so that such value includes the effect of bed forms (Falconer et al., 1991). It corresponds to a hydrodynamic roughness $z_{0}=2.5$ $\mathrm{mm}$, according to the $z_{0}=k_{s} / 30$ relation for rough walls (e.g. Lane and Ferguson, 2005), and to a Manning's coefficient $n=0.025$, according to the usual $n=k_{s}^{1 / 6} / 26$ formula (e.g. Christensen, 1992). Preliminary simulations found that minor differences in the flow fields were obtained by varying the roughness height up to a double (limit) value.

A uniform normal velocity was set at the inlet boundary, theoretical velocity distributions from river hydraulics not being appropriate for wind-driven flows. The mean annual discharge $-Q=20 \mathrm{~m}^{3} \mathrm{~s}^{-1}$ - the mean summer one - $Q=10 \mathrm{~m}^{3} \mathrm{~s}^{-1}$ - and a typical drought case $-Q=5 \mathrm{~m}^{3} \mathrm{~s}^{-1}$ - were tested. Fixed discharges were assigned as downstream boundary conditions at the Vasarone and Vasarina sluice gates. Most simulations considered the present layout with both outlets open, using a realistic 50\% - 50\% partition ratio (the average annual discharge concession of the Vasarina hydroelectric plant is $Q=10.65 \mathrm{~m}^{3} \mathrm{~s}^{-1}$ ). Others reproduced the past configuration with only the Vasarone outlet open. The inlets and outlets of the small secondary channels were not considered, their discharges being unknown, fluctuating and negligible, estimated to be on average $\sim 1 \mathrm{~m}^{3} \mathrm{~s}^{-1}$ overall for the inflows and $\sim 0.3$ $\mathrm{m}^{3} \mathrm{~s}^{-1}$ for the outflows.
Well-mixed conditions along the water depth were assumed, as verified by field measurements (Fenocchi, 2015). In fluvial lakes, the through-flowing current provides a background turbulence, preventing stratification even under no-wind conditions, so that baroclinic effects Rueda et al., 2003) can be neglected (Rubbert and Köngeter, 2005; Anderson et al., 2010; Schimmelpfennig et al., 2012). Indeed, small temperature gradients may be present in the deepest parts during summer drought periods. However, such weak stratification would affect the flow fields negligibly and would be destroyed by intense wind or rainfall events.

\section{Wind stress}

Horizontal flows in shallow basins are triggered by circulation vorticity (curl) sources, such as inhomogeneities in the lake bathymetry, in the coastline shape, in the wind stress field or in the vegetation cover, or because of the earth rotation (Józsa, 2014); another source is the momentum induced by inflows and outflows (Pilotti et al., 2014b). For small and very shallow lakes, as the Superior Lake of Mantua, the Coriolis effect is negligible (Fenocchi, 2015). In small basins placed in lowland regions, meteorological differences across the lake surface (Rueda et al., 2009) and disturbances by the surrounding topography (Toffolon and Rizzi, 2009) are not present. The wind stress curl then reduces to the asymptotic stress growth along the fetch triggered by the $2-3$ orders of magnitude drop of the aerodynamic roughness at the land-water interface and to its subsequent rise because of wave formation (Charnock, 1955). In fact, this produces an increase of both the wind intensity $(+20 \%-+30 \%$ with respect to the land value) and the wind drag coefficient. This influences the circulation layout of small lakes, in which the width of the basin matches the length scale of the wind stress growth to the fully-developed value (few kilometres).

The variation of the wind profile downwind of a roughness transition can be described semi-analytically by an Internal Boundary Layer (IBL) law, covering up for the need to take multiple measurements over the water surface (Podsetchine and Schernewski, 1999), such as Elliott's (1958) formula, expressing the development of the IBL thickness with the fetch $F$ :

$$
\delta_{b}(F)=0.75 F^{0.8} z_{0,2}(F)^{0.2}
$$

where $z_{0,2}(F)$ is the aerodynamic roughness of the downwind land cover, which for water is function of the fetch because of wave development. Here, multiple embedded IBL profiles (Krámer, 2006) were considered, reproducing the roughness transitions between land, water and emergent vegetation. A 2D code for wind stress fields calculation was implemented, its domain extending further upstream than the hydrodynamic model to consider correct fetch distances (Fig. 2). Both summer and winter con- 
ditions were simulated, the former ones being of most interest for the lake ecological dynamics, so that they are usually discussed in the results. The lotus flower cover was not included in the simulations of winter conditions, leaves being deciduous and only stems persisting; the other vegetation cover (Fig. 2) was instead always considered. Null wind stress was set over the leaf covers (Józsa, 2006).

Fixed aerodynamic roughness values $z_{0, l}=0.15 \mathrm{~m}$ (tall grass, see Józsa et al., 2007) and $z_{0, r}=0.08 \mathrm{~m}$ (Krámer, 2006) were adopted for the land and the emergent vegetation cover, respectively. The results in Józsa et al. (2007) reveal that negligible changes in the circulation layout should arise for land roughness values within the range for soil cover. A small wind direction variability and the lateral momentum exchange of air flow were taken into account by averaging 25 wind stress fields from $1^{\circ}$-spaced wind directions in the range $\pm 12^{\circ}$ from the main one, extending the approach of the Shore Protection Manual (SPM) (CERC, 1984). Sheltering by nearshore vegetation was also implemented in the wind stress model for the shoreline sections with trees. The Backward- and Forward-Facing Step (BFS and FFS) analogies (Ottesen Hansen, 1979) were adopted for windward and leeward separation zones, respectively, and the IBL theory was applied for the development of wind downstream of the reattachment point (Markfort et al., 2010, 2014), as if the windward shore were shifted. However, results showed a negligible influence of nearshore vegetation sheltering on the flow fields (Fenocchi, 2015), so that it is not included in the present simulations.

\section{Vegetation flow resistance}

Estimation of flow resistance by vegetation canopies is often critical for the modelling of shallow lakes. While in depth-averaged models the problem is solved by adopting increased bed roughness coefficients (e.g. Fischenich, 1997), more complex approaches are needed for 3D models. The most widespread solution is to add an external drag force to the momentum equation (Fischer-Antze et al., 2001; Choi and Kang, 2006):

$F_{D}=\frac{1}{2} \rho C_{D} A_{c} U_{c}^{2}$

which, in addition to the water density $\rho$, requires the estimation of: i) the drag coefficient $C_{D}$ for the vegetation canopy, a dynamic flow property and different from the one of a single stem, dependent on the definition of the projected area of the canopy in the flow direction $A_{c}$; ii) the undisturbed average velocities in the canopy area $U_{c}$. While these quantities are methodically defined in laboratory experiments with arrays of cylindrical obstacles, strong uncertainties arise in the case of natural randomlydistributed vegetation.
As an alternative, canopies were here considered as porous media (Oldham and Sturman, 2001; Hoffmann, 2004), adding a Forchheimer-type resistance source term in the momentum equation (Whitaker, 1996; CDadapco, 2014) for the cells within the main lotus flower island:

$\overrightarrow{F_{p}}=-\left(\frac{\mu}{\overline{\bar{K}}}+\rho \overline{\bar{\beta}}|\vec{v}|\right) \cdot \vec{v}$

where $\mu$ is the water dynamic viscosity, $\vec{v}$ is the velocity vector and $\overline{\bar{K}}$ and $\overline{\bar{\beta}}$ are the intrinsic permeability (Gebart, 1992) and inertial parameter (Zinke, 2011, 2012) principal tensors, respectively. Cylinder-like stems as the lotus flower have negligible vertical resistance. The horizontal components of the tensors are function of the stems diameter and spacing, which were estimated through a field survey as $d_{s} \approx 0.03 \mathrm{~m}$ and $l_{s} \approx 0.5 \mathrm{~m}$, respectively:

$K_{\text {hor }}=\frac{16\left[\left(l_{s}-d_{s}\right) / 2\right]^{5 / 2}}{9 \pi \sqrt{d_{s}}}=8.75 \cdot 10^{-2} m^{2}$

$\beta_{\text {hor }}=\frac{c_{L}^{3}\left(l_{s}-d_{s}\right)^{3}}{12 K^{2}}=3.85 \cdot 10^{-2} m^{-1}$

in which the coefficient $c_{L}{ }^{3}=0.034$, valid for dilute arrays with solid fraction $\phi \ll 0.02$, as here $\left(\phi=2.83 \cdot 10^{-3}\right)$. The Forchheimer-type formulation suits circulation modelling in lake canopies, as it considers both the viscous and the inertial parts of resistance (Zinke, 2011). No modification was done to the $k$ and $\varepsilon$ equations in the canopy regions.

\section{Surface waves}

Under shallow and transitional water conditions, surface waves, in addition to generating bottom stress, also alter circulations, as they increase bottom friction in a spatially-heterogeneous fashion (Grant and Madsen 1979). The friction coefficient enhancement factor $\lambda_{w c}$ was here calculated with the formulation by Wu et al. (2010), introduced iteratively into the hydrodynamic solver in specific simulations:

$\lambda_{w c}=\frac{\sqrt{U+c_{w} U_{w}^{2}}}{U}$

where $c_{w} \approx 0.5$ is an empirical coefficient and $U$ and $U_{w}$ are the depth-averaged velocity magnitude and the peak bottom wave orbital velocity, respectively. The depth-averaged velocities were calculated from the magnitudes in the bottom cells $u_{I L}$, assuming a logarithmic profile (Deltares, 2014):

$$
U=u_{1 L} \frac{\ln \frac{30 h}{e k_{s a}}}{\ln \frac{30 y_{G, 1 L}}{k_{s a}}}
$$

in which $h$ is the flow depth, $e$ is Euler's number, $k_{s a}=\lambda_{w c}{ }^{3}$ $k_{s}$ is the augmented roughness height (Fenocchi, 2015) and $y_{G, I L}$ is the wall distance to the centroid of the bottom cell. The coefficient 30 arises from the $z_{0}=k_{s} / 30$ relation 
(see Boundary conditions paragraph). The peak wave orbital velocities are instead obtained according to the linear wave theory:

$U_{w}=\frac{\pi H_{r m s}}{T_{a} \sinh \frac{2 \pi h}{L_{w}}}$

where $H_{r m s}$ is the root-mean-square wave height, $T_{a}$ is the average wave period and $L_{w}$ is the effective wavelength. The SPM formulas (CERC, 1984) for fetch-limited shallow and transitional water conditions, which take into account wave damping by bottom friction, were used to compute $H_{r m s}$ and $T_{a}$. These equations model the transition to deep water conditions, so that they capture the residual wave-bottom interaction persisting for $h / L_{w}>1 / 2$ (Borell Lövstedt and Larson, 2010), as needed for the modelling of the Superior Lake of Mantua.

The local wind and fetch values from the IBL wind stress model and the depths from the bathymetry were used in the SPM formulas, producing spatial maps of the wave parameters. The main characters of wave heterogeneity, i.e. growth with fetch and dependence on water depth, are hence taken into account without adopting specific codes for wave climate modelling. Such approximation is suitable herein, as the purpose is only an estimation of the effects of surface waves.

No waves were assumed in the canopy area in the simulations of summer conditions, due to the lack of supporting wind stress and to the strong hampering of external waves by the lotus flower leaves bed and stems. In winter simulations, instead, damping of the root-mean-square wave height through the stems was modelled with the Mendez and Losada (2004) approach:

$H_{r m s}=\frac{H_{r m s, 0}}{1+\xi x}$

in which $\xi$ is a function of the flow depth and of the waves and canopy properties and $H_{r m s, 0}$ is a reference, nondamped root-mean-square wave height. Here, the nondamped heights calculated with the coupled SPM/IBL model were considered as $H_{r m s, 0}$ instead of the values at the canopy edge. Thus, the contrast between wave damping by vegetation and development with fetch is reproduced (Suzuki et al., 2012).

The maximum wave bottom stresses were also computed according to the linear wave theory:

$\tau_{w m}=\frac{1}{2} \rho f_{w} U_{w}^{2}$

where the wave friction factor $f_{w}$ was parameterised as (Luettich et al., 1990):

$f_{w}=2 R e_{w}^{-0.5}$

this expression being valid in the observed laminar waves range, i.e. for wave Reynolds numbers $\operatorname{Re}_{w}=U_{w} A_{b m} / v$ $<10^{4}$, with the bottom wave amplitude $A_{b m}$ defined according to the linear wave theory:
$A_{b m}=\frac{H_{r m s}}{2 \sinh \frac{2 \pi h}{L_{w}}}$

Finally, the time $t_{d}$ needed for steady-state waves to develop was calculated with the SPM formula for shallow and transitional waters (CERC, 1984):

$t_{d}=537\left(\frac{g}{W_{A}}\right)^{4 / 3} T_{a}^{7 / 3}$

in which $g$ is the gravity acceleration and $W_{A}=0.71 W_{10}^{1.23}$ is the wind-stress factor, with $W_{10}$ being the wind intensity at $10 \mathrm{~m}$ height.

\section{Wind climate}

A statistical analysis of the wind climate of the Superior Lake of Mantua was performed to identify typical wind scenarios, using 2011-2013 5-minute wind data from the MeteoMincio weather station in Rivalta sul Mincio ( 7 $\mathrm{km}$ west of the centre of the lake). The high-frequency data prevents the smoothing of brief storm events, ensuring accurate statistics. Being the anemometer placed $13 \mathrm{~m}$ above the soil level, standard $W_{10, l}$ values over land were calculated from the turbulent wind profile equation as:

$W_{10, l}=W_{13, l} \frac{\ln \frac{10}{z_{0, l}}}{\ln \frac{13}{z_{0, l}}}$

where $W_{13, l}$ is the wind intensity over land at $13 \mathrm{~m}$ height and $z_{0, l}=0.15 \mathrm{~m}$ (see Wind stress paragraph).

The resulting wind rose is shown in Fig. 3. The main wind axis lies in the $80^{\circ}-260^{\circ}$ direction, parallel to the riverine axis of the lake, both wind directions being common throughout the year. This causes significant interactions between the wind and the through-flowing current in shaping circulations to occur.

Standard wind (exceedance probability $\mathrm{P}=50 \%$ ) and ordinary storm $(\mathrm{P}=0.5 \%$, roughly corresponding to 441 hour events per year) overland intensities $W_{10, l}$ were defined for both main wind directions, isolating the data subsets for the two relative $10^{\circ}$-wide wind rose sectors and calculating over each of them the relevant intensities defined above. For easterly wind, standard wind $W_{10, l}=1.94 \mathrm{~m} / \mathrm{s}$ and ordinary storm $W_{10, l}=10.10 \mathrm{~m} / \mathrm{s}$ were obtained, while for westerly wind $W_{10, l}=1.68 \mathrm{~m} / \mathrm{s}$ and $W_{10, l}=6.77 \mathrm{~m} / \mathrm{s}$ were found, respectively.

\section{Layout of the numerical simulations}

Steady-state simulations of typical wind and discharge conditions were performed to evaluate the circulation patterns and the influence of wind and through-flowing discharge under different regimes. The brief adaptation time scales of small shallow lakes allow the achievement of quasi-steady flow conditions in days with standard winds (Falconer et al., 1991). This is rarely 
the case of storm events, which are mostly shorter than the adaptation time of circulations (see Simulation of impulse transients paragraph).

The four defined wind scenarios were simulated under both summer and winter conditions, i.e. respectively considering or omitting wind sheltering by the lotus flower cover (see Wind stress paragraph), for the three selected discharges (see Boundary conditions paragraph). The influence of the Vasarina outlet on circulations was estimated, comparing the flow fields for the present and past outlets configurations. This analysis was undertaken as it was deemed by local authorities that the opening of the new outlet would have favoured water flushing in the south-eastern part of the lake, improving its ecological quality.

To concisely point out differences in the velocity direction along the vertical, two velocity vectors are shown for each location in the displayed flow fields: on the free surface (nearly always the longest one) and $2.0 \mathrm{~m}$ below, where maximum return current velocities would occur if the basin were flat parallelepipedal (Heaps, 1984).

In all simulations, the local water residence time within each mesh element was computed with a purelyadvected passive scalar, supplying a unit mass flow rate source of tracer to each cell at every iteration (CD-adapco,
2014). The effects of turbulent diffusion on such calculation were found to be negligible in the present simulations. The spatial distribution of the water residence time highlights the different degrees of stagnation within the basin, providing a much more complete and realistic information than the theoretical complete-mixing value $\left(T_{\text {rtheor }}=\right.$ water volume/outflowing discharge) (Pilotti et al., 2014a). The computed water residence times were depthaveraged to generate distribution maps, as negligible variations were found to occur along the water depth.

Wave parameters for the wind scenarios were estimated, performing simulations with friction factor enhancement by wave-bottom interaction to evaluate the influence of waves on circulations. Wave bottom stresses were computed and compared with the ones of the current. The times needed for the development of steady-state waves were also calculated and compared to the duration of storm events.

Impulse transient simulations were last performed to estimate the adaptation time scales of circulations to storm events. Storm wind stress distributions were impulsively applied on the steady-state flow fields of summer standard wind simulations, monitoring the evolution of circulations over time up to new equilibrium conditions. All the four

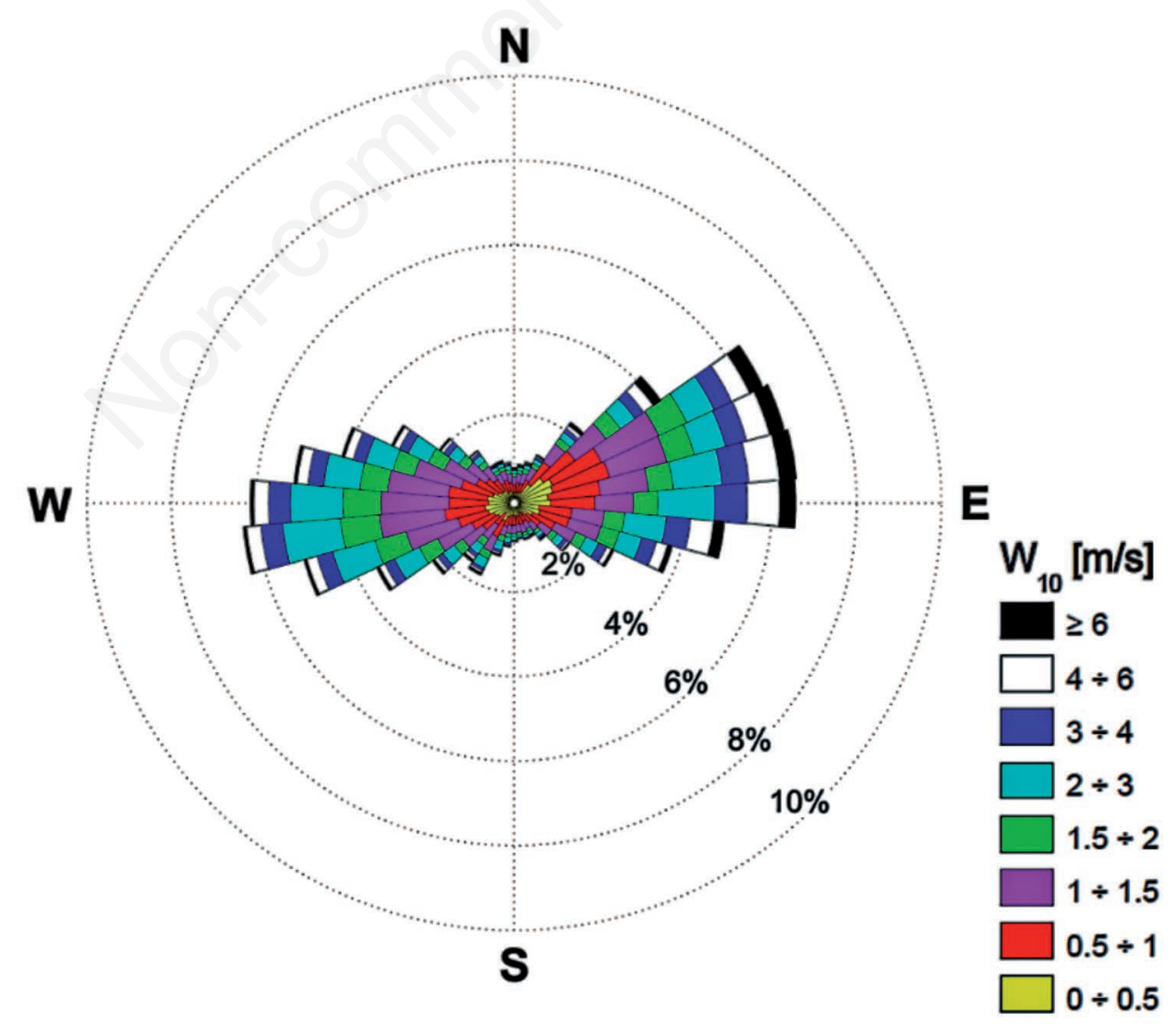

Fig. 3. Wind rose for the 2011-2013 MeteoMincio weather station data. 
combinations between the two standard wind and storm wind scenarios (see Wind climate paragraph) were tested. The time step in the transient simulations was set to $t_{s}=10 \mathrm{~s}$.

\section{RESULTS AND DISCUSSION}

\section{Standard circulation layouts}

Simulations with summer standard wind conditions and the mean annual discharge $Q=20 \mathrm{~m}^{3} \mathrm{~s}^{-1}$ show that the flow in the Superior Lake of Mantua is wind-influenced. Circulations start developing where the cross section widens, with water velocities in the order of $v \approx 0.05 \mathrm{~m} \mathrm{~s}^{-1}$. Small differences in the velocity direction along the vertical are present, more prominent in recirculating, slow-flow areas. The abrupt variation of wind stress at the edge of the canopy contributes to the formation of gyres. Inside the vegetated area, water flows in the upwind direction with velocities of few $\mathrm{mm} \mathrm{s}^{-1}$ because of sheltering, balancing water displacement by wind in exposed areas. The interposed canals across the lotus flower island are shown ineffective at reactivating circulations, the spatial scale of lake currents being much larger than the width of the passages.

Under summer easterly standard wind conditions (Fig. 4), large gyres are reproduced north of the lotus

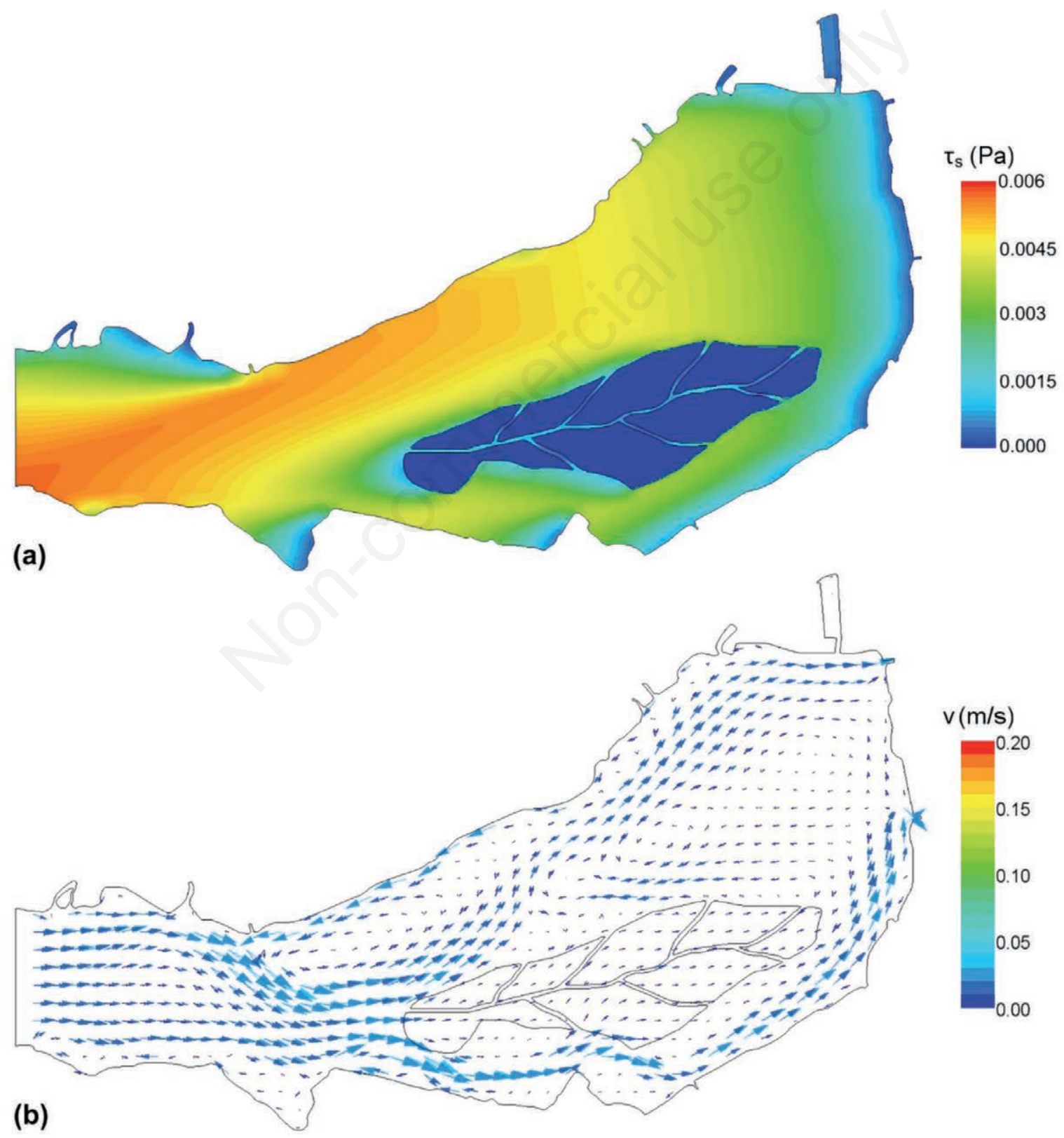

Fig. 4. Wind stress (a) and flow (b) fields for the summer easterly standard wind and $Q=20 \mathrm{~m}^{3} \mathrm{~s}^{-1}$ simulation. 
flower island, triggered by topographic and wind stress curl. Most notably, a large part of the through-flowing current channels in wind-sheltered areas, flowing first along the northern shore, then shifting towards the channel south of the lotus flower island and last leaning against the eastern shore towards the Vasarina. A large stagnating area is located downstream of the island. The free surface superelevation in the downwind (i.e., upstream) part of the lake is in the order of $\Delta \eta \approx 10^{-4} \mathrm{~m}$, one order of magnitude larger than under no-wind conditions, showing the preponderance of wind force over bottom friction.
With summer westerly standard wind conditions (Fig. 5), the flow channels along the central longitudinal section of the lake, north of the lotus flowers island, owing to the combined effect of the riverine current and the wind thrust, this also being the most wind-exposed area of the basin. Recirculations are present along the northern shore, while a large stagnating region forms in the southern part of the basin, because of the porous patch and of wind sheltering. Such stagnation is critical for the ecosystem, as it leads to the accumulation of phytoplankton in the area (Pinardi et al., 2015). Wind force still prevails over head losses in determining the surface

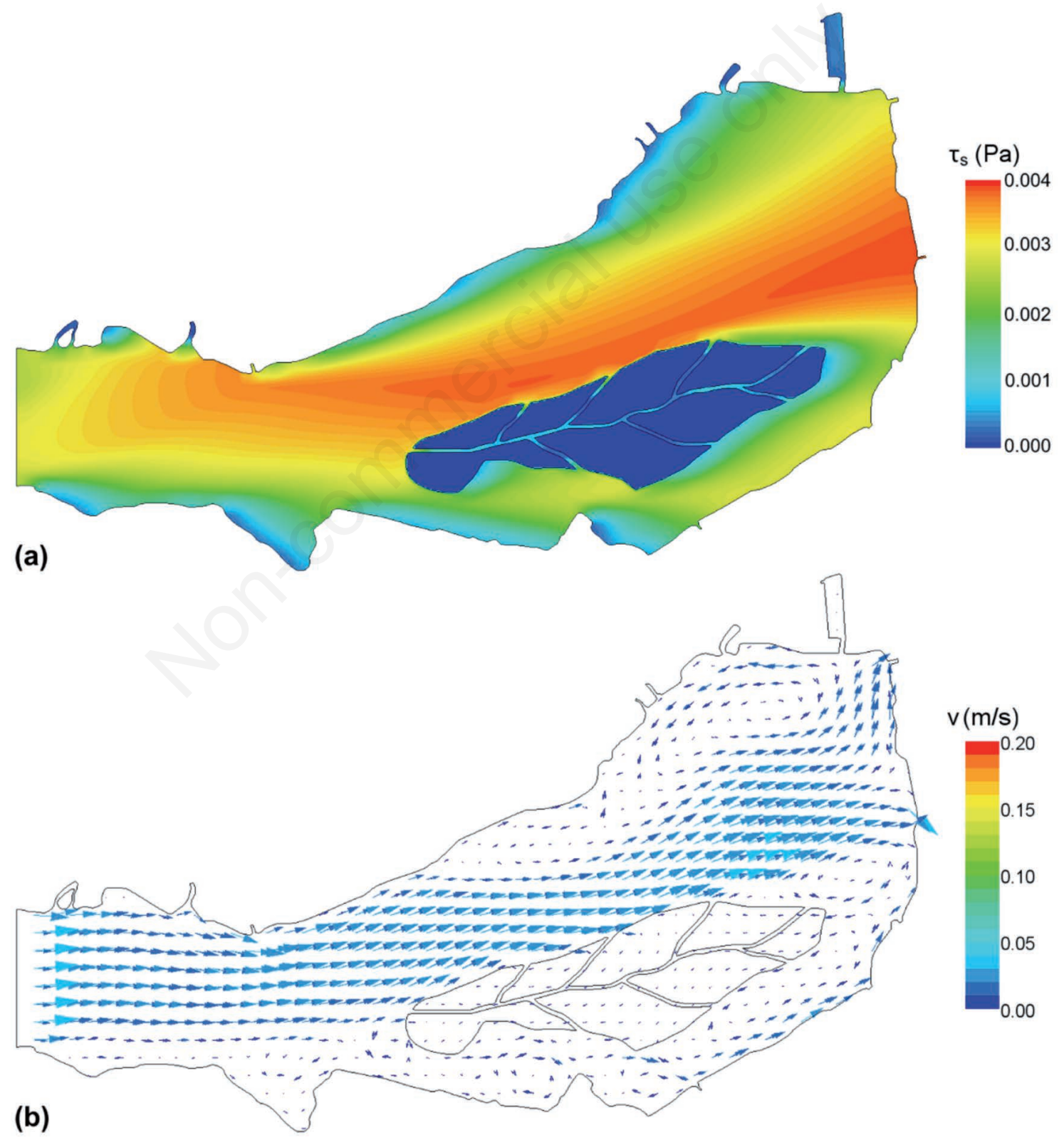

Fig. 5. Wind stress (a) and flow (b) fields for the summer westerly standard wind and $Q=20 \mathrm{~m}^{3} \mathrm{~s}^{-1}$ simulation. 
setup, with superelevation at the downstream (and downwind) edge of the basin around $\Delta \eta \approx 10^{-4} \mathrm{~m}$.

The flow field for the related westerly standard wind simulation under winter conditions is shown in Fig. 6 (such wind direction is the most common during that season). As wind stress grows also within the vegetation patch, the values attained at the downwind side are slightly larger than in the summer situation, resulting also in a marginally higher setup. Nevertheless, the circulation layout shows very small differences, as the flow resistance of the vegetation stems is still present, except for reduced stagnation south of the lotus flower island, that area not being sheltered by wind. Inside the canopy, water flows in the downwind direction with velocities of few $\mathrm{cm} \mathrm{s}^{-1}$ in the close proximity of the free surface, due to wind thrust, while a return flow of few $\mathrm{mm} \mathrm{s}^{-1}$ is attained below in the most part of the flow depth. Such behaviour is due to wind-induced turbulence within the porous medium rapidly extinguishing along the vertical. The flow inside the lotus flower island appears then to be far more shaped by canopy flow resistance than by wind sheltering.

\section{Storm and drought conditions}

Under storm wind and mean annual discharge conditions, the increase of wind stress by two orders of magnitude compared to standard wind results in simulated water velocities up to $v \approx 0.20 \mathrm{~m} \mathrm{~s}^{-1}$. Differences in the flow direction along the water depth are more noticeable, with almost complete inversions occurring in slow-flow areas. Nevertheless, circulations in the horizontal plane are still prevailing. In particular, more recirculating flow fields result, which, together with the higher water velocities, produce higher mixing. Wind setup is in the order of $\Delta \eta \approx 10^{-2}$ $\mathrm{m}$, two orders of magnitude larger than for standard wind.

Under summer easterly ordinary storm wind conditions (Fig. 7a), surface water is generally advected in the windward direction, whereas the bottom current flows more in the downstream direction. For summer westerly storm wind, flow channelisation at the centre of the lake is less prominent than for standard wind, so that more developed circulations form, also in the southern region. While small variations result in the flow fields for standard wind conditions and $Q=10 \mathrm{~m}^{3} \mathrm{~s}^{-1}$ compared to the ones for the mean annual discharge, striking differences occur in the drought $Q=5 \mathrm{~m}^{3} \mathrm{~s}^{-1}$ case. The latter circulation layouts are almost coincident to the ones for storm wind and $Q=20 \mathrm{~m}^{3} \mathrm{~s}^{-1}$, except for the lower velocities (Fig. 7b). The size of stagnating areas increases considerably with smaller discharges. In the summer easterly standard wind and $Q=5 \mathrm{~m}^{3} \mathrm{~s}^{-1}$ simulation (Fig. $7 \mathrm{~b}$ ), recirculations in the northern part of the basin form two large slow-flow regions, which are echoed by higher values in the depth-averaged local water residence time map (Fig. 8a). Stagnation under drought discharge is even more critical for summer westerly standard wind (Fig. 8b), as weak currents determine a vast enclosed stagnant area in the whole southern part of the lake, with very high residence times. However, under real-world conditions, the turnover of wind directions and intensities, together with discharge variations, trigger water mixing (Fabian and Budinski, 2013 ), so that the actual water residence times in stagnat-

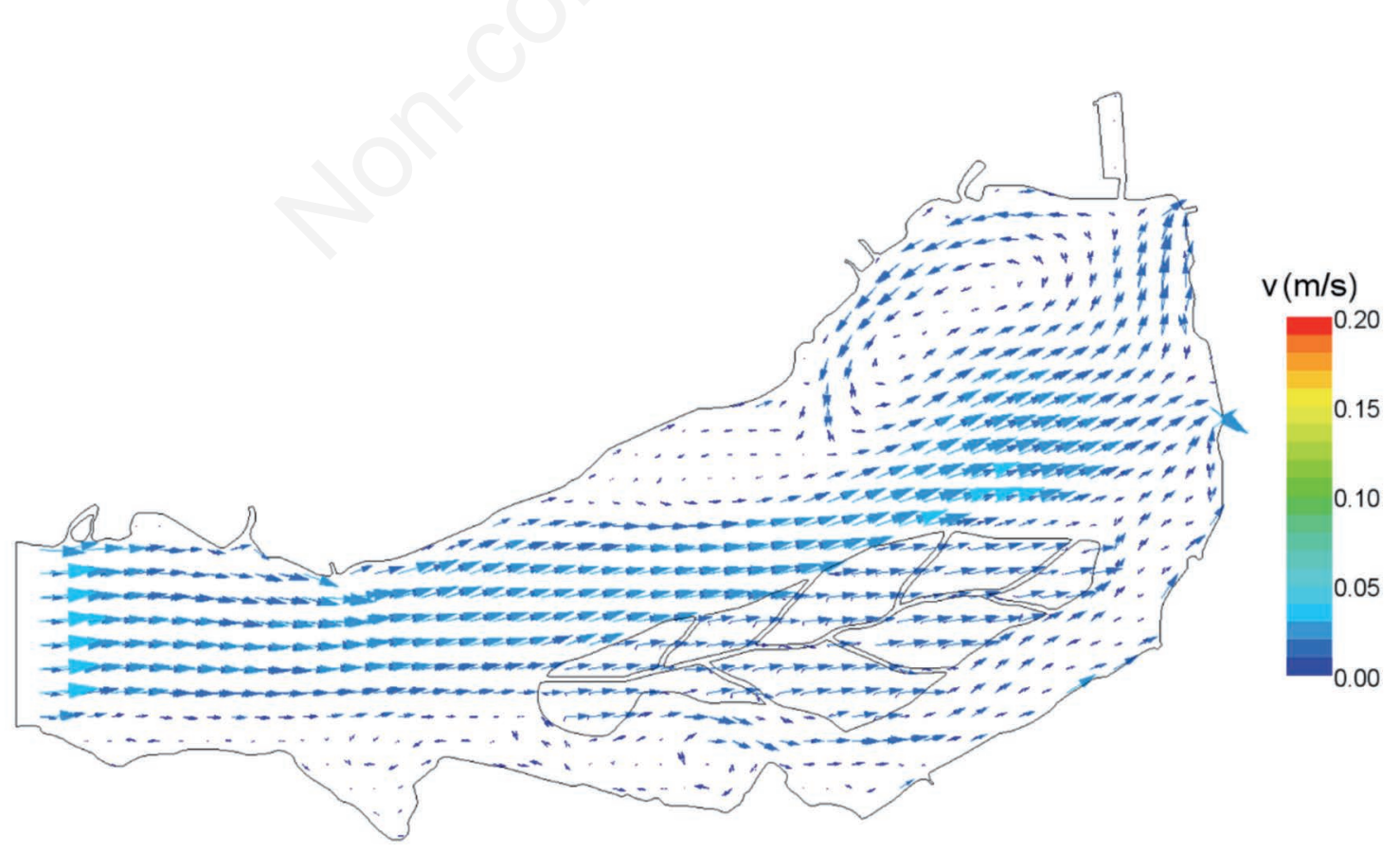

Fig. 6. Flow field for the winter westerly standard wind and $Q=20 \mathrm{~m}^{3} \mathrm{~s}^{-1}$ simulation. 
ing areas are significantly lower than those in Fig. 8.

From these results, the circulation layouts of shallow fluvial lakes appear mostly shaped by the relative direction and intensity of wind and riverine current forces, whereas flow velocities depend on their absolute values. Although lower discharges may increase the efficiency of wind mixing, the decrease of water velocity and the rise of water residence time lead to more stagnant conditions. This explains the vital importance of adequate flow rates for the ecosystems of shallow fluvial lakes in the lowland reach of heavily-impacted river basins.

\section{Water residence time distribution}

The Residence Time Distribution (RTD) curves for the summer easterly standard wind runs (Fig. 9a) are close to exponential complete-mixing ones (Pilotti et al., 2014a), while significantly altered distributions are attained for the summer westerly standard wind cases (Fig. $9 \mathrm{~b})$, because of extended stagnation in the southern part of the lake. This results in average simulated water residence times more than quadruple of the theoretical estimates. For both wind directions, lower discharges

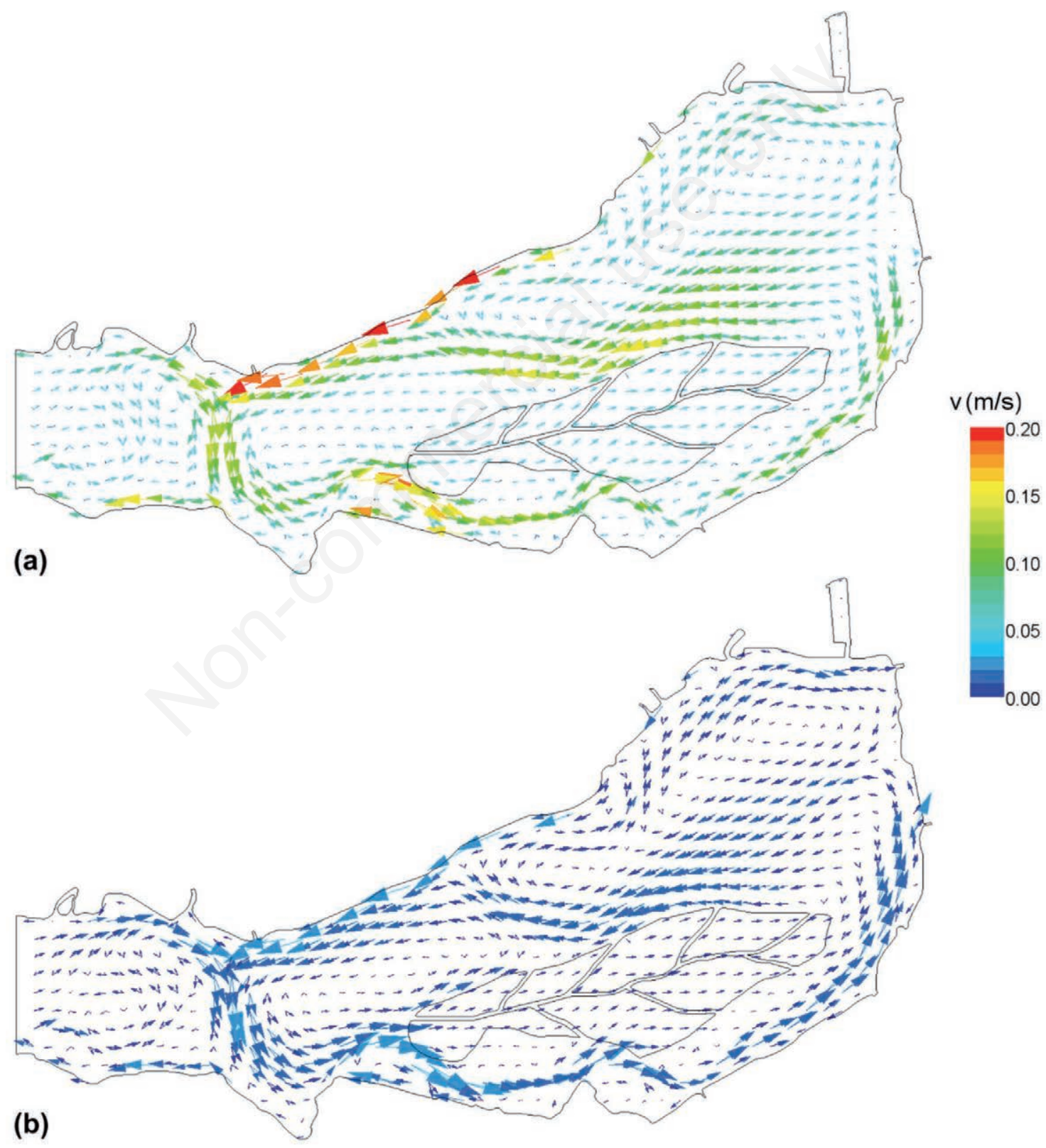

Fig. 7. Flow fields for the summer easterly ordinary storm wind and $Q=20 \mathrm{~m}^{3} \mathrm{~s}^{-1}$ (a) and for the summer easterly standard wind and $Q=5 \mathrm{~m}^{3} \mathrm{~s}^{-1}(\mathrm{~b})$ simulations. 
cause a clear increase in the water residence times.

The flatter simulated RTD curves in Fig. 9c (which also shows the no-wind case) confirm the higher mixing caused by storm winds, destroying stagnant areas. Winter conditions also determine lower stagnation, in particular for westerly wind. Water renewal is in fact slower during the summer because of wind sheltering by the leaves of the lotus flowers, which combines with water abstraction in determining critical conditions.

\section{Influence of the secondary outlet}

Fig. 9 a,b also show the RTD curves for the summer simulations with only the Vasarone outlet active. The open- ing of the Vasarina actually increases the residence times for easterly wind conditions. A positive effect is possibly obtained for westerly wind and $Q=20 \mathrm{~m}^{3} \mathrm{~s}^{-1}$, as a $\sim 20 \%$ decrease of the renewal time in the stagnant southern part of the lake is obtained. Such benefit vanishes for the lower discharges, since no relevant improvement occurs for westerly wind and $Q=5 \mathrm{~m}^{3} \mathrm{~s}^{-1}$. Similar differences hold for both wind directions under winter conditions.

Therefore, the opening of the Vasarina should not have a large impact, neither a significant positive effect, on lake circulations, and would even be slightly detrimental under certain situations. The reason behind this result is twofold: i) the spatial scale of lake circulations is much larger than

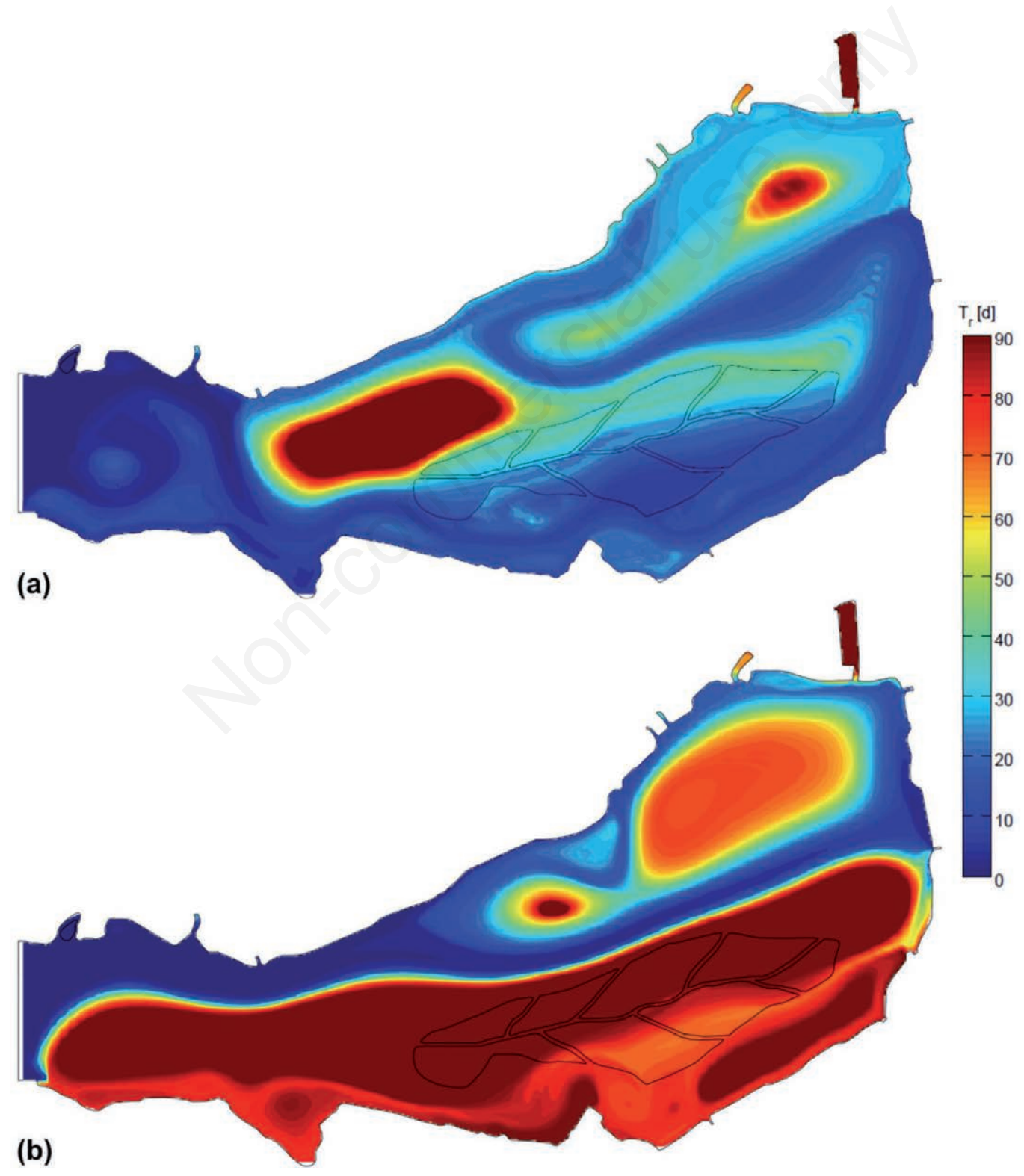

Fig. 8. Depth-averaged local water residence times maps for the summer easterly (a) and westerly (b) standard wind and $Q=5 \mathrm{~m}^{3} \mathrm{~s}^{-1}$ simulations. 
the pull effect of the Vasarina, which is limited to a $200-$ $300 \mathrm{~m}$ wide neighbourhood of the outlet; ii) the influence of wind on current patterns, which is not altered by the outlets configuration. In any case, differences are larger for the higher discharges, as the through-flowing current towards the outlets is more significant, when stagnation is however less critical. As a result, the only effective method to improve water flushing in the Superior Lake of Mantua is to increase the through-flowing discharge, minimising excess upstream water abstraction from the Mincio River.

\section{Surface waves analysis}

For summer easterly ordinary storm wind conditions, root-mean-square wave heights (Fig. 10a) up to $H_{r m s} \approx 0.24 \mathrm{~m}$ (significant wave heights up to $H_{s}=\sqrt{2}$
$H_{r m s} \approx 0.34 \mathrm{~m}$ ) and average wave periods (Fig. 10b) up to $T_{a} \approx 1.8 \mathrm{~s}$ are estimated in the most wind-exposed region. The calculated times for the formation of steady-state waves are $t_{d}<22 \mathrm{~min}$, so that they would establish during typical storm events and the use of their parameters for the present evaluations is reasonable. The maximum wave bottom stress (Fig. 11a) is null in most of the lake, in which deep water conditions hold. Transitional conditions are achieved in the most wind-exposed and shallowest regions in the upstream part of the lake, with maximum wave bottom stress $\tau_{w m} \approx 0.05 \mathrm{~N} \mathrm{~m}^{-2}$. The bottom shear stress due to circulatory motions obtained from the hydrodynamic simulation $\left(Q=20 \mathrm{~m}^{3} \mathrm{~s}^{-1}\right)$ (Fig. 11b) is in the same order of magnitude of the wave bottom stress, $\tau_{c} \approx 10^{-2}-10^{-1} \mathrm{~N} \mathrm{~m}^{-2}$, yet it is spread across the whole basin. Negligible modifications of the roughness

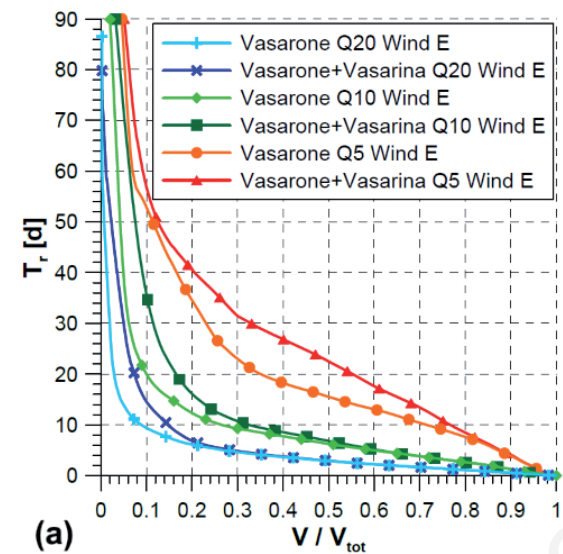

(a) $\begin{array}{rrrrrrr}0 & 0.1 & 0.2 & 0.3 & 0.4 & 0.5 & 0.6 \\ & & & & & & \end{array} / V_{\text {tot }}$

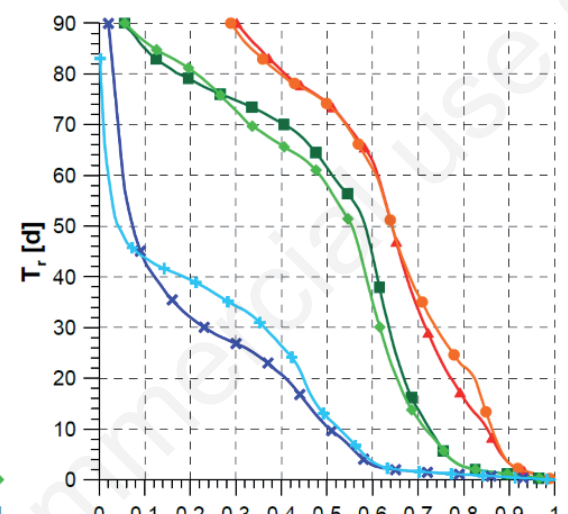

(b)
$\mathrm{V} / \mathrm{V}_{\text {tot }}$

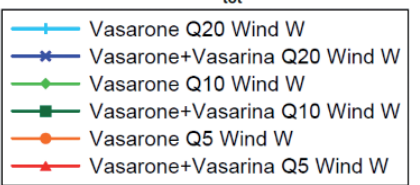

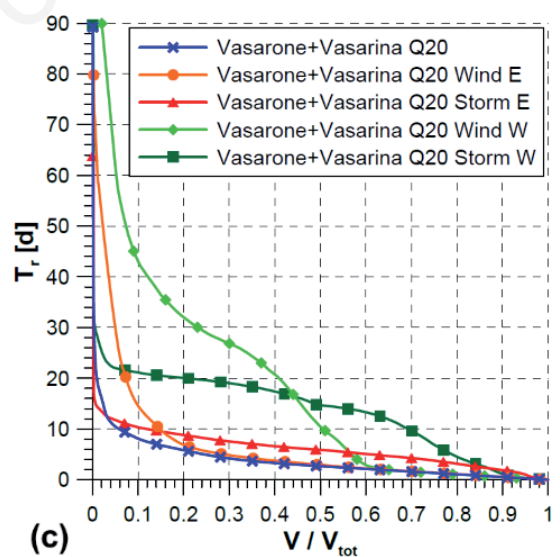

(c) $\mathrm{V} / \mathrm{V}_{\mathrm{tot}}$

Fig. 9. RTD curves for different discharges and outlets configuration for summer easterly (a) and westerly (b) standard wind simulations. c) RTD curves for different wind intensities and directions for summer $Q=20 \mathrm{~m}^{3} \mathrm{~s}^{-1}$ simulations.

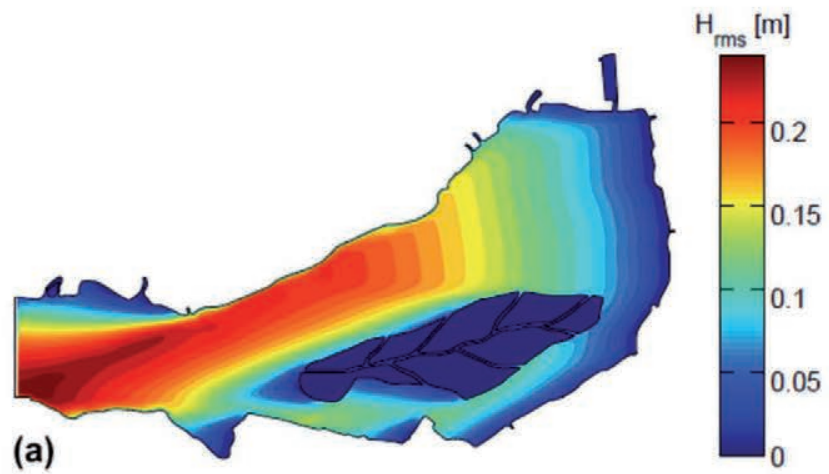

Fig. 10. Root-mean-square wave height (a) and average wave period (b) fields for the summer easterly ordinary storm wind and $Q=20$

(b)

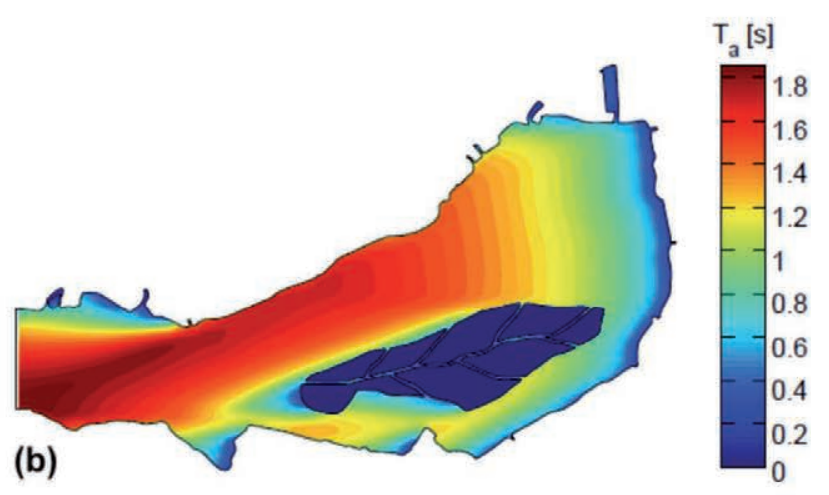
$\mathrm{m}^{3} \mathrm{~s}^{-1}$ simulation. 
coefficient result, so that the flow field is also marginally altered.

Due to the lower wind intensity, smaller waves (up to $H_{r m s} \approx 0.15 \mathrm{~m}$ ), lower wave bottom stresses (up to $\tau_{w m} \approx 0.02$ $\left.\mathrm{N} \mathrm{m}^{-2}\right)$ and higher steady-state waves formation times $\left(t_{d}\right.$ $<28 \mathrm{~min}$ ) are obtained for summer westerly storm wind conditions, so that the flow field is even less influenced. Under winter conditions, the computed canopy damping opposes IBL wind development, resulting in almost constant wave heights inside the vegetation patch. Slightly higher maximum wave heights are calculated (up to $H_{r m s} \approx 0.28 \mathrm{~m}$ for easterly storm wind), due to the marginally higher maximum wind stress, nevertheless causing negligible variations to the flow field. Wave-bottom interaction clearly does not occur for standard wind inten- sities, root-mean-square wave heights up to $H_{r m s} \approx 0.02$ $0.03 \mathrm{~m}$ being obtained. The shear stress of the current is in the order of $\tau_{c} \approx 10^{-3} \mathrm{~N} \mathrm{~m}^{-2}, 1-2$ orders of magnitude smaller than for storm winds.

Wave-induced bottom stress should then hardly be the main cause of resuspension during storms in the Superior Lake of Mantua, being in the same entity of current bottom stress, instead of overwhelming it by an order of magnitude, as common in many shallow lakes (Luettich et al., 1990; Teeter et al., 2001). This is due to the small size of the basin, which prevents the formation of waves high enough to considerably interact with the bottom. Even if bottom stresses have been estimated, a specific investigation on sedimentation and resuspension processes in the Superior Lake of Mantua would be of particular interest,

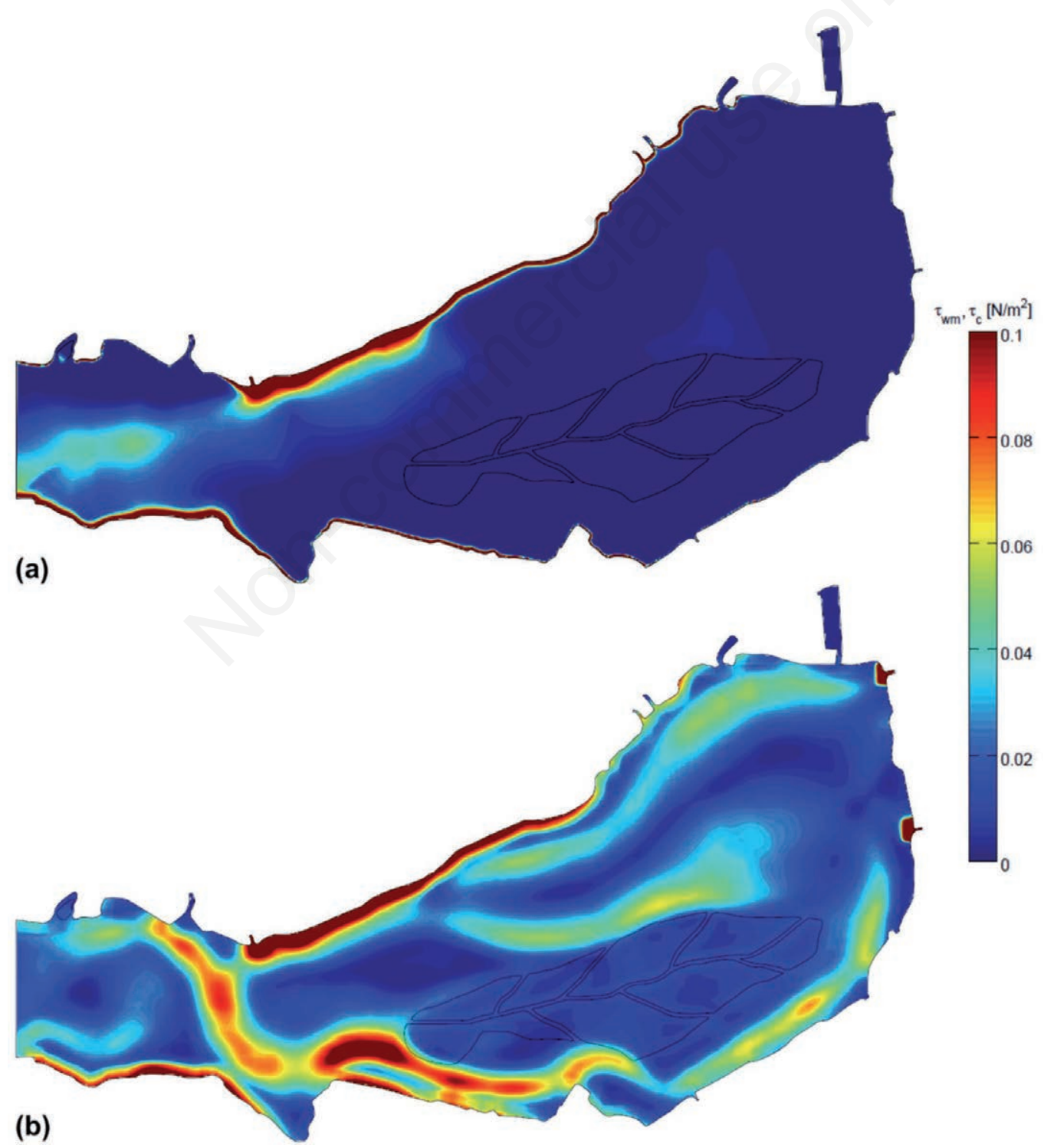

Fig. 11. Maximum wave (a) and current (b) bottom stress fields for the summer easterly ordinary storm wind and $Q=20 \mathrm{~m}^{3} \mathrm{~s}^{-1} \mathrm{simulation}$. 
as knowledge on the bottom dynamics of sediments, nutrients and pollutants is central to the improvement of the ecological state.

\section{Simulation of impulse transients}

The adaptation dynamics of the flow fields to impulse storm wind stresses are here discussed on the base of simulation results. The storm wind force is first absorbed by the surface water layer, which accelerates in the wind direction, reaching a saturation velocity after a characteristic time $t_{c} \approx 1-2 \mathrm{~min}$. The storm wind stress is then gradually passed to the water depth below, as was observed by Ciraolo et al. (2004) in their simulations, generating a circulation layout in the vertical plane with windward surface flow and return bottom current, which erases the previous flow structure. This transformation is complete after a characteristic time $t_{c} \approx 10-20 \mathrm{~min}$ from the beginning of the simulation. After the whole water volume has absorbed the storm wind stress, approaching the equilibrium surface setup, circulations in the horizontal plane start to replace those in the vertical one, as was reproduced in the simulations by Curto et al. (2006). This process ends after $t_{c} \approx 2-3 \mathrm{~h}$ from the beginning, a longer time than the duration of most storms. The final steady-state configuration is eventually reached asymptotically after $t_{c} \approx 5-6 \mathrm{~h}$. The simulations confirm the adaptation time scales of few hours typical of shallow lakes. Stable storm wind circulations could therefore be reached only on daylong strong wind events, which sometimes occur in the Po River Plain, especially during spring and autumn.

The evolution in time of the mean water velocity magnitude over all the model cells $\mu(v)$ for the four tested transient summer simulations is shown in Fig. 12. The graph shows an initial steep rise, corresponding to the absorption of wind energy by the water volume. A subsequent drop is attained as circulations in the vertical plane shift to the horizontal one, part of the kinetic energy being converted into potential energy due to the establishment of wind setup. The mean velocity then restarts to grow asymptotically to the equilibrium value, which is reached together with the achievement of stable circulations in the horizontal plane, and is equal to 4-5 times the initial one. Notably, the simulations with the same storm wind forcing, which start from circulations determined by opposite standard wind directions, retain some differences up to the achievement of the final steady state. This shows that the transient evolution of the flow field in a basin with such an inertia depends strongly on the initial configuration, not only on the external forces.

The current bottom stress grows with the velocity, depending on its square value, reaching its equilibrium after the same characteristic time, which is much longer than the duration of most storms.

\section{CONCLUSIONS}

A framework for the numerical modelling of the hydrodynamics of a shallow fluvial lake with extended vegetation patches, the Superior Lake of Mantua, has been presented. A 3D model was adopted to properly reproduce the interactions between wind and riverine through-flow in shaping circulations. Wind stress growth with fetch and emergent vegetation sheltering, relevant for small basins, were accounted with a multiple IBL approach. Canopy flow resistance was implemented with a porous medium model, needing only geometrical parameters. Surface wave parameters maps were computed with the SPM formulas, using local wind and flow depth values and including also wave damping by vegetation. Such maps were employed to include wave-current interaction into the hydrodynamic model. The herein presented methodology can be useful for studies on small shallow basins and dammed river reaches, as a basis for comparisons and further improvements.

A hydrodynamic characterisation of the Superior Lake of Mantua was then performed, generally evaluating the physics of the basin and guiding future research on it, first of all a field investigation to directly validate model results. Typical wind and discharge regimes were identified, and were found to determine flows influenced by both forces under standard wind and mean discharge conditions and mainly wind-driven ones during storms or droughts, with strongly different layouts. Circulations were found to be deeply affected by the main lotus flower island under both flowering (summer) and bare stems (winter) conditions. Stable westerly winds would cause extended water stagnation for drought discharges, leading

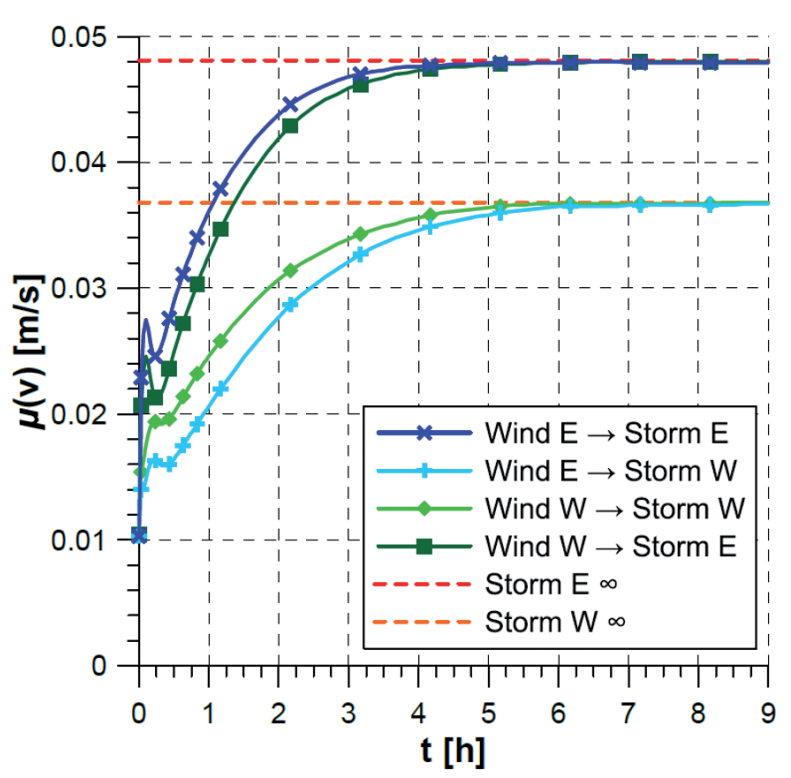

Fig. 12. Evolution in time of the mean water velocity magnitude over all the model cells for the impulse transient simulations. 
to potential hypertrophication. The newly-opened secondary outlet of the lake, the Vasarina, was evaluated to bring no net improvement in water flushing. Surface waves were estimated to be barely relevant for the resuspension and circulatory dynamics during storm events, in contrast with what usually occurs in shallow lakes. The adaptation times of flow fields to storm wind forcing were evaluated to be longer than the duration of most storm events.

\section{ACKNOWLEDGMENTS}

We would like to thank M. Pinardi (CNR-IREA) and M. Bartoli (University of Parma) for the field surveys. We also thank P. Favalli of the MeteoMincio weather station for making wind data freely available. We last recognise the work of the anonymous reviewers, who have considerably helped to improve the contents and the presentation of the manuscript.

\section{REFERENCES}

Anderson EJ, Schwab DJ, Lang GA, 2010. Real-time hydraulic and hydrodynamic model of the St. Clair River, Lake St. Clair, Detroit River System. J. Hydraul. Eng. 136:507-518.

Bolpagni R, Bresciani M, Laini A, Pinardi M, Matta E, Ampe EV, Giardino C, Viaroli P, Bartoli M, 2014. Remote sensing of phytoplankton-macrophyte coexistence in shallow hypereutrophic fluvial lakes. Hydrobiologia 737:67-76.

Borell Lövstedt C, Bengtsson L, 2008. The role of non-prevailing wind direction on resuspension and redistribution of sediments in a shallow lake. Aquat. Sci. 70:304-313.

Borell Lövstedt C, Larson M, 2010. Wave damping in reed: field measurements and mathematical modeling. J. Hydraul. Eng 136:222-233

Bresciani M, Rossini M, Morabito G, Matta E, Pinardi M, Cogliati S, Julitta T, Colombo R, Braga F, Giardino C, 2013. Analysis of within- and between day chlorophyll-a dynamics in Mantua Superior Lake, with a continuous spectroradiometric measurement. Mar. Freshwater Res. 64:303-316.

CD-adapco, 2014. STAR-CCM+ v9.02 User Guide. Online manual, Melville, USA.

CERC (Coastal Engineering Research Center), 1984. Shore Protection Manual. 4. US Army Corps of Engineers, Washington, USA: 559 pp.

Charnock H, 1955. Wind stress on a water surface. Q. J. Roy. Meteor. Soc. 81:639-640.

Choi S-U, Kang H, 2006. Numerical investigations of partlyvegetated open channel flows using the Reynolds stress model. J. Hydraul. Res. 44:203-217.

Christensen BA, 1992. Replacing Hydraulic Radius in Manning's Formula in Open Channels, p. 271-287. In: B.C. Yen (ed.), Channel flow resistance: centennial of Manning's formula. Water Resources Publications, Highlands Ranch, USA.

Ciraolo G, Lipari G, Napoli E, Józsa J, Krámer T, 2004. Threedimensional numerical analysis of turbulent wind-induced flows in the Lake Balaton (Hungary), p. 661-669. In: W.S.J. Uijttewaal and G.H. Jirka (eds.), Shallow flows. Research presented at the Int. Symp. on Shallow Flows, Delft, Netherlands, 2003. Taylor \& Francis/Balkema, Rotterdam.
Curto G, Józsa J, Napoli E, Lipari G, Krámer T, 2006. Large scale circulations in shallow lakes, p. 83-104. In: M. Brocchini and F. Trivellato (eds.), Vorticity and turbulence effects in fluid structure interaction - An application to hydraulic structure design. Transactions on State-of-the-art in Science and Engineering 25. WIT Press, Southampton, UK.

Deltares, 2014. Delft3D-FLOW User Manual. Ver. 3.14.33641. Delft: $710 \mathrm{pp}$.

Elliott WP, 1958. The growth of the atmospheric internal boundary layer. Eos T. Am. Geophys. Un. 39:1048-1054.

Fabian J, Budinksi L, 2013. Horizontal mixing in the shallow palic lake caused by steady and unsteady winds. Environ. Model. Assess. 18:427-438.

Falconer RA, George DG, Hall P, 1991. Three-dimensional numerical modelling of wind-driven circulation in a shallow homogeneous lake. J. Hydrol. 124:59-79.

Fenocchi A, 2015. Circulation dynamics in a shallow fluvial lake - The case of the Superior Lake of Mantua. Ph.D. Thesis, University of Pavia, Italy.

Fenocchi A, Petaccia G, Sibilla S, 2016. Modelling flows in shallow (fluvial) lakes with prevailing circulations in the horizontal plane: limits of 2D compared to 3D models. J. Hydroinform. DOI: 10.2166/hydro.2016.033. Available online: http://jh.iwaponline.com/content/early/2016/05/14/ hydro.2016.033

Fischenich JC, 1997. Hydraulic Impacts of Riparian Vegetation; Summary of the Literature. Technical Report EL-97-9. US Army Corps of Engineers, Waterways Experiment Station, Washington: $63 \mathrm{pp}$.

Fischer-Antze T, Stoesser T, Bates P, Olsen NRB, 2001. 3D numerical modelling of open-channel flow with submerged vegetation. J. Hydraul. Res 39:303-310.

Gebart BR, 1992. Permeability of unidirectional reinforcements for RTM. J. Compos. Mater. 26(8):1100-1133.

George DG, Heaney SI, 1978. Factors influencing the spatial distribution of phytoplankton in a small productive lake. J. Ecol. 66(1):133-155.

Grant WD, Madsen OS, 1979. Combined wave and current interaction with a rough Bottom. J. Geophys. Res. 84(C4): 1797-1808.

Heaps NS, 1984. Vertical structure of current in homogeneous and stratified waters, p. 152-207. In: K. Hutter (ed.), Hydrodynamics of lakes. CISM Lectures No. 286. Springer, New York.

Hodges BR, 2014. Hydrodynamical modeling. In: S.A. Elias (ed.), Reference module in earth systems and environmental sciences. Elsevier.

Hoffmann MR, 2004. Application of a Simple space-time averaged porous media model to flow in densely vegetated channels. J. Porous Media 7:183-191.

Jones RI, Fulcher AS, Jayakody JKU, Laybourn-Parry J, Shine AJ, Walton MC, Young JM, 1995. The horizontal distribution of plankton in a deep, oligotrophic lake - Loch Ness, Scotland. Freshwater Biol. 33:161-170.

Józsa J, 2006. Shallow lake hydrodynamics - Theory, measurement and numerical model applications. Mundus-Euroaquae lecture notes. Budapest University of Technology and Economics: $87 \mathrm{pp}$.

Józsa J, 2014. On the internal boundary layer related wind stress curl and its role in generating shallow lake circulations. J. Hydrol. Hydromech. 62:16-23. 
Józsa J, Krámer T, Napoli E, 2007. The impact of terrain roughness and water level changes on wind-induced shallow lake circulation patterns. In: Proc. 5th Int. Symp. on Environmental Hydraulics, Tempe, USA.

Krámer T, 2006. Solution-adaptive 2D modelling of wind-induced lake circulation. Ph.D. Thesis, Budapest University of Technology and Economics, Hungary.

Lane SN, Ferguson RI, 2005. Modelling reach-scale fluvial flows, p. 217-269. In: P.D. Bates, S.N. Lane and R.I. Ferguson (eds.), Computational fluid dynamics: applications in environmental hydraulics. J. Wiley \& Sons, Chichester, UK.

Luettich RA, Harleman DRF, Somlyódi L, 1990. Dynamic behavior of suspended sediment concentrations in a shallow lake perturbed by episodic wind events. Limnol. Oceanogr. 35:1050-1067.

Markfort CD, Pereza ALS, Thill JW, Jaster DA, Porté-Agel F, Stefan HG, 2010. Wind sheltering of a lake by a tree canopy or bluff topography. Water Resour. Res. 46:1-13.

Markfort CD, Porté-Agel F, Stefan HG, 2014. Canopy-wake dynamics and wind sheltering effects on Earth surface fluxes. Environ. Fluid Mech. 14:663-697.

Mendez FJ, Losada IJ, 2004. An empirical model to estimate the propagation of random breaking and nonbreaking waves over vegetation fields. Coast. Eng. 51:103-118.

Neuendorf KKE, Mehl JP, Jackson JA, 2005. Glossary of geology. 5. American Geological Institute, Alexandria, USA: 779 pp.

Oldham CE, Sturman JJ, 2001. The effect of emergent vegetation on convective flushing in shallow wetlands: Scaling and experiments. Limnol. Oceanogr. 46:1486-1493.

OLL (Osservatorio dei Laghi Lombardi), 2005. [Qualità delle acque lacustri in Lombardia].[Report in Italian]. $1^{\circ}$ Rapporto OLL 2004 - Aggiornamento 2005. Fondazione Lombardia per l'Ambiente e CNR-IRSA, Milan, Italy: 354 pp.

Ottesen Hansen NE, 1979. Effects of boundary layers on mixing in small lakes, p. 341-356. In: W.H. Graf and C.H. Mortimer (eds.), Hydrodynamics of lakes. Developments in Water Science 11. Elsevier, Amsterdam, Netherlands.

Pilotti M, Simoncelli S, Valerio G, 2014a. Computing the transport time scales of a stratified lake on the basis of Tonolli's model. J. Limnol. 73:551-561.

Pilotti M, Valerio G, Gregorini L, Milanesi L, Hogg CAR, 2014 b. Study of tributary inflows in Lake Iseo with a rotating physical model. J. Limnol. 73:131-145.

Pinardi M, Bartoli M, Longhi D, Viaroli P, 2011. Net autrophy in a fluvial lake: the relative role of phytoplankton and floating-leaved macrophytes. Aquat. Sci. 73:389-403.

Pinardi M, Fenocchi A, Giardino C, Sibilla S, Bartoli M, Bresciani M, 2015. Assessing potential algal blooms in shallow fluvial lakes by combining hydrodynamic modelling and Remote-Sensed images. Water 7:1921-1942.

Pinel-Alloul B, 1995. Spatial heterogeneity as a multiscale characteristic of zooplankton community. Hydrobiologia 300301:17-42.

Podsetchine V, Schernewski G, 1999. The influence of spatial wind inhomogeneity on flow patterns in a small lake. Water Res. 33:3348-3356.
Rubbert S, Köngeter J, 2005. Measurements and three-dimensional simulations of flow in a shallow reservoir subject to small-scale wind field inhomogeneities induced by sheltering. Aquat. Sci. 67:104-121.

Rueda FJ, Schladow SG, Monismith SG, Stacey MT, 2003. Dynamics of large polymictic lake. I: Field observations. J. Hydraul. Eng. 129:82-91.

Rueda FJ, Vidal J, Schladow SG, 2009. Modeling the effect of size reduction on the stratification of a large wind-driven lake using an uncertainty-based approach. Water Resour. Res. 45:1-15.

Schimmelpfennig S, Kirillin G, Engelhardt C, Nützmann G, 2012. Effects of wind-driven circulation on river intrusion in Lake Tegel: modeling study with projection on transport of pollutants. Environ. Fluid Mech 12:321-339.

Shih TH, Liou WW, Shabbir A, Yang Z, Zhu J, 1994. A New k$\varepsilon$ Eddy viscosity model for high Reynolds number turbulent flows-model development and validation. NASA Technical Memorandum 106721. NASA Lewis Research Center, Cleveland, USA: 32 pp.

de Souza Cardoso L, da Motta Marques D, 2009. Hydrodynamics-driven plankton community in a shallow lake. Aquat. Ecol. 43:73-84.

Suzuki T, Zijlema M, Burger B, Meijer MC, Narayan S, 2012. Wave dissipation with layer schematization in SWAN. Coast. Eng. 59:64-71.

Teeter AM, Johnson BH, Berger C, Stelling G, Scheffner NW, Garcia MH, Parchure TM, 2001. Hydrodynamic and sediment transport modeling with emphasis on shallow-water, vegetated areas (lakes, reservoirs, estuaries and lagoons). Hydrobiologia 444:1-23.

Toffolon M, Rizzi G, 2009. Effects of spatial wind inhomogeneity and turbulence anisotropy on circulation in an elongated basin: A simplified analytical solution. Adv. Water Resour. 32:1554-1566.

Verhagen JHG, 1994. Modeling phytoplankton patchiness under the influence of wind-driven currents in lakes. Limnol. Oceanogr. 39:1551-1565.

Wang Y, Hutter K, Bäuerle E, 2001. Barotropic response in a lake to wind forcing. Ann. Geophys. 19:367-388.

Whitaker S, 1996. The Forchheimer equation: a theoretical development. Transport Porous Med. 25:27-61.

Wiens JA, 1989. Spatial scaling in ecology. Funct. Ecol. 3: 385-397.

Wu W, Sánchez A, Zhang M, 2010. An implicit 2-D depth-averaged finite-volume model of flow and sediment transport in coastal waters. Paper $n^{\circ}$ Sediment 23. In: J. McKee Smith and P. Lynett (eds.), Proc. $32^{\text {nd }}$ Int. Conf. on Coastal Engineering, Shanghai, China. Curran Associates, Red Hook.

Zinke P, 2011. Modelling of flow and levee depositions in a freshwater delta with natural vegetation. Ph.D. Thesis, Norwegian University of Science and Technology.

Zinke P, 2012. Application of a porous media approach for vegetation flow resistance, p. 301-308. In: R. Murillo Muñoz (ed.), Proc. Congr. River Flow 2012. 1. San José, Costa Rica. CRC Press/Balkema, Leiden. 